\title{
EFFECT OF SOME MICROCLIMATIC STRESSORS AND FOOD DEPRIVATION ON HEALTH STATUS, MATERNAL BEHAVIOUR AND NEWLY BORN DEVELOPMENT AND VIABILITY IN BALADI, BOSCAT AND CALIFORNIA RABBITS
}

\author{
Moatz A.Abdel-Rahman ${ }^{* *}$; Moustafa .M. Ahmed ${ }^{*}$ and Madeha Darwish ${ }^{* * *}$ \\ *Department of Animal hygiene, Faculty of Veterinary Medicine, Assiut University. \\ ** Animal behaviour and management.
}

\begin{abstract}
:
Changes in health status, behavioral patterns, serum cortisol level of the rabbit does as well as the development, viability and survival of their newly born young were studied. 60 multiparous, 1.5-2 years old rabbit does were used in this investigation. 20 does were of Baladi breed, 20 does were of Bouscat breed while the last 20 does were of California breed. Each doe was housed separately in a suitable galvanized wire cage and provided with a nest box and nesting materials. Animals of each breed were randomly assigned into 4 groups, each of 5 does. A group of each breed was housed together forming four experimental groups. These groups were housed in a well-ventilated and welllighted separate suitable room under the prevalent environmental conditions. Fresh drinking water was freely available allover the experiment. Before starting the experiment, does of each experimental group were freely fed the pelleted commercial concentrates mixture for a 14 days preliminary period and the residue was weighed daily to determine the average daily food intake per doe. Several mating took place during the preliminary period where each doe was transferred to the pen of a buck of the same breed (more than one year old) and returned to her own pen after mating. The first experimental group (group I) was maintained under the prevalent environmental conditions (temperature was $21 \pm 2^{\circ} \mathrm{C}$ and relative humidity was $60 \pm 3 \%$ ) and received the average daily amount of food throughout the experiment and was used as a control one. The second experimental group (group II) was subjected to a significant increase in the surrounding temperature and relative humidity where the room temperature was maintained at $33 \pm 1^{\circ} \mathrm{C}$ and the relative humidity was also maintained at $80 \pm 2 \%$ throughout the experiment using electric heaters and fogmaster tri-jet, model 6208 and received a daily amount of food as in case of control group. The third experimental group (group III) received a daily amount of food equals to $75 \%$ of that consumed by the control one while the fourth experimental group (group IV) received a daily amount of food equals to $50 \%$ of that consumed by the control one however, both of the $3^{\text {rd }}$ and $4^{\text {th }}$ groups were maintained under the same environmental conditions as in case of control group conditions (temperature was $21 \pm 2^{\circ} \mathrm{C}$ and relative humidity was $60 \pm 3 \%$ ). Rectal temperature, respiratory rate and the condition of the mucous membranes of the experimented does were recorded for three successive days / week along the experiment. Blood samples were collected from the ear vein of the does under experiment and the sera of the collected samples were separated and were estimated for their levels of cortisol. Maternal and abnormal behaviour of the examined does were recorded. Moreover, litter size, viability and survival of young were determined. The obtained results revealed that, adverse environmental conditions as well as maternal feed deprivation had been found to act as stress factors on the does, specially the foreign breeds and affected significantly on their health status and altered their maternal behaviour which reflected
\end{abstract}


significantly on the development, viability and survival of the newly born young rabbits.

\section{INTRODUCTION :}

In recent years, more attention has been focused on the need to recognize and control adverse effects on animals. Similarly, attention is being paid to the need to improve and enrich the environment in which animals spend their lives. There is, however, still a great deal of scope for improving current practice for the benefit of animal welfare. Such improvements can also enhance the quality of scientific research, since suffering and distress in animal can result in physiological disorders.

Stress is defined biologically as the force producing or tending to produce deformation in the body and it may be climatic, nutritional or due to pathogens and toxins (Lee, 1966; Hafez, 1968 and Scott, 1981). Animals which are usually kept under conditions of artificial environment are usually stressed and undergo to what is called suffering which is defined as behavioural and managemental problems of economic impacts which badly affect the animal health and performance ( Mervat, 1993).

Rabbits are very sensitive to climatic stress and are especially vulnerable to heat stroke especially overweight and heavily furred breeds. Therefore, rabbits should be kept in the coolest and least humid area of the house where there is a good air circulation. The best surrounding temperature and relative humidity $\%$ for rabbit breeding are $15-21^{\circ} \mathrm{C}$ and $55-60 \%$, respectively (Sandford, 1996). Moreover, nutritional stress or underfeeding has a very obvious effect on rabbit health and production, either flesh, kindle or fur (Parigi-Bini, 1990). However, undernourishment of pregnant animals affects significantly on their maternal behaviour. Nest building, retrieving, physical contact and suckling of the newly born young as well as incidence of cannibalism was found to be affected significantly following maternal starvation (Scott, 1981 and Mervat, 1993). At the same time, maternal starvation is considered as one of the most important factors affecting the survival of the neonates. Limiting the amount of food given to the pregnant animal results in a decrease in the level of energy intake and so reduces their hepatic glycogen levels and tends to decrease the skeletal muscle glycogen in the progeny at birth and so decreases the newborn chances of survival (Ojamaa et al., 1980 and Ezekwe, 1981).

Therefore, the present study is dealing with the effect increased surrounding temperature and relative humidity as well as undernourishment of the pregnant rabbit does of different breeds on their health status, maternal behaviour and development and survival of their newborn young.

\section{MATERIALS AND METHODS :}

\section{1- Experimental animals:}

60 multiparous, 1.5-2 years old does were used in this investigation. 20 does were of Baladi breed with average weight of $2-2.5 \mathrm{~kg}, 20$ does were of Bouscat breed with average weight of $3.5-4 \mathrm{~kg}$ while the last 20 does were of California breed with average weight of 3.5-4 kg. Each doe was housed separately in a suitable galvanized wire cage and provided with a nest box and nesting materials. Animals of each breed were randomly assigned into 4 groups, each of 5 does. 4 groups, each of 5 does. A group of each breed was housed together forming four experimental groups. These groups were housed in a wellventilated and well-lighted separate suitable room under the prevalent environmental conditions. Fresh drinking water was freely available allover the experiment. 


\section{2- Experimental design :}

Before starting the experiment, does of each experimental group were freely fed the pelleted commercial concentrates mixture for a 14 days preliminary period and the residue was weighed daily to determine the average daily food intake per doe (250 gm for Baladi breed and $400 \mathrm{gm}$ for Boscat and California breeds). Moreover, several mating took place during the preliminary period where each doe was transferred to the pen of a buck of the same breed (more than one year old) and returned to her own pen after mating. A successful mating being achieved by noticing the doe lifting her hind quarters towards the buck and after mating, the buck being fallen over side way giving a special cry. In this experiment, the conception rate was $100 \%$ as all does were palpated at 10 days postmating and all were pregnant.

The first experimental group (group I) was maintained under the prevalent environmental conditions (temperature was $21 \pm 2^{\circ} \mathrm{C}$ and relative humidity was $60 \pm 3 \%$ ) and received the average daily amount of food throughout the experiment and was used as a control one. Temperature $\left({ }^{\circ} \mathrm{C}\right)$ and relative humidity (\%) were measured using SATO thermometer \& hygrometer, SATO Keiryoki MFG Co., LTD, Japan. (the best room temperature and humidity for rabbit breeding lie between 15$21^{\circ} \mathrm{C}$ and $55-60 \%$, respectively according to Sandford, 1996).

The second experimental group (group II) was subjected to a significant increase in the surrounding temperature and relative humidity where the room temperature was maintained at $33 \pm 1{ }^{\circ} \mathrm{C}$ and the relative humidity was maintained at $80 \pm 2 \%$ throughout the experiment using electric heaters and fogmaster tri-jet, model 6208. Moreover, animals of this group received a daily amount of food as in case of control group.
The third experimental group (group III) received a daily amount of food equals to $\mathbf{7 5 \%}$ of that consumed by the control one (Tonkiss and Smart, 1983 and Mervat, 1993). However, The fourth experimental group (group IV) received a daily amount of food equals to $\mathbf{5 0 \%}$ of that consumed by the control one (Tonkiss and Smart, 1983 and Mervat, 1993). Both of the $3^{\text {rd }}$ and $4^{\text {th }}$ groups were maintained under the same environmental conditions as in case of control group conditions (temperature was $\mathbf{2 1} \pm \mathbf{2}$ ${ }^{\circ} \mathrm{C}$ and relative humidity was $60 \pm 3 \%$ ).

\section{3- Health status :}

Where the rectal temperature, respiratory rates and the condition of the mucous membranes were recorded according to Afifi and Daghash (1999) for three successive days / week during the experiment. Rectal temperature was measured by a clinical thermometer inserted into the rectum for a minute at a depth of $2 \mathrm{~cm}$. Respiratory rates were recorded by counting the flank movements per minute using a hand counter. However, the condition of the mucous membranes was examined by investigation of the vulva.

\section{4- Serum cortisol level of the does :}

Blood samples were collected from the ear vein of the does under experiment according to Suckow \& Douglas (1997) and Afifi \& Dachash (1999). At the end of the experimental period, a blood sample (about $3 \mathrm{ml}$ ) was collected from each doe from the ear vein at 9:00 a.m. morning on the wall of a centrifuge tube. The sera of the collected samples were separated by centrifugation at 3000 r.p.m. for 30 minutes and were freezed at $-20^{\circ} \mathrm{C}$ until analysis. The harvested sera were estimated for their levels of cortisol using TDxFLx system with fluorescence polarization and competitive binding techniques according to Dandliker \& Feigen (1970) and Dandliker \& Saussure (1973). 


\section{5-Viability of the newly born young rabbits :}

The development of the newly born young was measured according to Mervat (1993) and Afifi \& Daghash (1999) as follows :

1-Litter size (the number of the newly born young at birth).

2-Viability of young at birth (number of live newly born young at birth).

3-Percentage of death of young after one week of birth.

4-Percentage of death of young after two weeks of birth.

5-Percentage of death of young at weaning (four weeks old).

\section{6- Maternal behaviour:}

The maternal behaviour of the does under experiment was examined as follows:

1-Presence or absence of nest in the nesting box (Numan, 1978).

2-Measuring of retrieving: The retrieving was measured according to Jakubowski and Terkel (1986) where the does living with their newly born young rabbits were separated away 30 minutes prior to the test and then reunited with their young after being scattered infront of the nest and the dam was observed continuously for 30 minutes. The newly born retrieval was scored if the dam carried at least two of her newly born young to the nest site.

3-Physical contact: The dam was considered good if she was in contact with her all newly born young or all except one or two (Mervat, 1993).

4-Percentage of suckling: Where the percentage of suckled newly born young at the first day post-partum was recorded (Mervat, 1993).

\section{7-Abnormal behavioural patterns of} the does:

1-Cannibalism: - Where the percentage of the does that neglected and ate their newly born young was recorded (Willis, 1991).

2-Fur chewing: - Where the number of does that chewed their fur was recorded. Fur chewing was explained by Cheeke (1987) as small mouthfuls of fur that are bitten off and eventually swallowed completely.

3-Any abnormal behaviour that the does might show during the experiment.

\section{8- Statistical analysis:}

Statistical analyses of the collected data were carried out according to procedures of completely random design, SAS (1995).

\section{RESULTS :}

The results of the study were illustrated in Tables 1,2,3,4 and 5 .

\section{DISCUSSION :}

Livestock lives within an environment complicated by a multitude of factors encompassing both physical and psychological aspects of the animal's surroundings. Thermal environment has a strong influence on animals where air temperature having the primary effect, but altered by humidity and others. Animals acclimatize within limits for the variations of the effective ambient temperature by altering food intake, metabolism and heat dissipation, which intern alter the partition of dietary energy by the animal and the net result is an altered energetic efficiency. 
Table (1): Health status of the examined does

\begin{tabular}{|c|c|c|c|c|c|}
\hline \multirow{2}{*}{ Measurements } & \multirow{2}{*}{ Breed } & \multicolumn{4}{|c|}{ Treatments } \\
\hline & & Group I & Group II & Group III & Group IV \\
\hline \multirow{3}{*}{ Rectal Temperature $\left({ }^{\circ} \mathrm{C}\right)$} & Baladi & $38.8 \pm 0.2^{a}$ & $39.1 \pm 0.1^{a}$ & $38.6 \pm 0.2^{a}$ & $37.8 \pm 0.1^{b}$ \\
\hline & Bouscat & $38.6 \pm 0.1^{\mathrm{a}}$ & $39.8 \pm 0.2^{b}$ & $37.8 \pm 0.1^{c}$ & $37.7 \pm 0.1^{\mathrm{c}}$ \\
\hline & California & $38.9 \pm 0.1^{\mathrm{a}}$ & $39.9 \pm 0.2^{b}$ & $37.8 \pm 0.1^{c}$ & $37.6 \pm 0.1^{\mathrm{c}}$ \\
\hline \multirow{3}{*}{$\begin{array}{l}\text { Respiratory rates } \\
\text { (Movement / min.) }\end{array}$} & Baladi & $86 \pm 2^{a}$ & $93 \pm 2^{b}$ & $88 \pm 3^{b}$ & $110 \pm 3^{b}$ \\
\hline & Bouscat & $88 \pm 2^{\text {a }}$ & $115 \pm 4^{b}$ & $112 \pm 2^{b}$ & $118 \pm 2^{b}$ \\
\hline & California & $90 \pm 3^{a}$ & $110 \pm 3^{b}$ & $108 \pm 2^{b}$ & $112 \pm 2^{b}$ \\
\hline \multirow{3}{*}{$\begin{array}{l}\text { Mucous membranes } \\
\text { (Colour) }\end{array}$} & Baladi & Rosy red & Rosy red & Rosy red & Pale \\
\hline & Bouscat & Rosy red & Congested & Pale & Pale \\
\hline & California & Rosy red & Congested & Pale & Pale \\
\hline
\end{tabular}

Table (2): Serum cortisol level ( $\mu \mathrm{g} / \mathrm{dl})$ of the examined does

\begin{tabular}{|c|c|c|c|c|c|}
\hline \multirow[t]{2}{*}{ Measurement } & \multirow[t]{2}{*}{ Breeds } & \multicolumn{4}{|c|}{ Treatments } \\
\hline & & Group I & Group II & Group III & Group IV \\
\hline \multirow{3}{*}{ Serum cortisol level } & Baladi & $1.54 \pm 0.1^{a}$ & $1.72 \pm 0.1^{a}$ & $2.10 \pm 0.1^{a}$ & $4.18 \pm 0.1^{b}$ \\
\hline & Bouscat & $1.61 \pm 0.1^{a}$ & $4.63 \pm 0.1^{b}$ & $5.13 \pm 0.1^{b}$ & $4.91 \pm 0.1^{b}$ \\
\hline & California & $1.59 \pm 0.1^{a}$ & $5.11 \pm 0.1^{b}$ & $5.42 \pm 0.1^{b}$ & $5.12 \pm 0.1^{b}$ \\
\hline
\end{tabular}

Table (3): Viability of the newly born young rabbits.

\begin{tabular}{|c|c|c|c|c|c|}
\hline \multirow{2}{*}{ Item } & \multirow{2}{*}{ Breeds } & \multicolumn{4}{|c|}{ Treatments } \\
\hline & & Group I & Group II & Group III & Group IV \\
\hline \multirow{3}{*}{ Litter size (No. / birth) } & Baladi & $5-6$ & $5-6$ & 4-6 & 4-6 \\
\hline & Bouscat & $7-8$ & $6-8$ & $6-8$ & $6-8$ \\
\hline & California & $6-8$ & $5-7$ & $5-6$ & $6-7$ \\
\hline \multirow{3}{*}{ Viability at birth (\%) } & Baladi & $80^{a}$ & $80^{a}$ & $75^{a}$ & $65^{b}$ \\
\hline & Bouscat & $80^{\mathrm{a}}$ & $70^{b}$ & $60^{b}$ & $50^{c}$ \\
\hline & California & $80^{\mathrm{a}}$ & $70^{b}$ & $60^{b}$ & $50^{c}$ \\
\hline \multirow{3}{*}{ Death after one week (\%) } & Baladi & $0^{a}$ & $20^{b}$ & $20^{b}$ & $20^{b}$ \\
\hline & Bouscat & $0^{a}$ & $40^{b}$ & $30^{b}$ & $40^{b}$ \\
\hline & California & $0^{a}$ & $50^{b}$ & $30^{c}$ & $50^{b}$ \\
\hline \multirow{3}{*}{ Death after two weeks $(\%)$} & Baladi & $0^{a}$ & $25^{b}$ & $20^{b}$ & $20^{b}$ \\
\hline & Bouscat & $0^{a}$ & $50^{b}$ & $50^{b}$ & $60^{b}$ \\
\hline & California & $0^{a}$ & $55^{b}$ & $50^{b}$ & $60^{b}$ \\
\hline \multirow{3}{*}{ Death at weaning $(\%)$} & Baladi & $0^{a}$ & $30^{b}$ & $25^{b}$ & $50^{c}$ \\
\hline & Bouscat & $0^{a}$ & $60^{b}$ & $60^{b}$ & $80^{c}$ \\
\hline & California & $0^{a}$ & $60^{b}$ & $60^{b}$ & $75^{c}$ \\
\hline
\end{tabular}

Figures in the same raw with different superscripts differs significantly $(\mathrm{p}<0.01)$.

Group I = Control (Temp. was $21{ }^{\circ} \mathrm{C}$, RH was $60 \%$ and received the average daily amount of food).

Group II = Temp. was $33{ }^{\circ} \mathrm{C}$ and $\mathrm{RH}$ was $80 \%$.

Group III = Received a daily amount of food equals to $75 \%$ of that consumed by the control one.

Group $\mathrm{V}=$ Received a daily amount of food equals to $50 \%$ of that consumed by the control one. 
Table (4): Maternal behaviour of the examined does .

\begin{tabular}{|c|c|c|c|c|c|}
\hline \multirow[t]{2}{*}{ Item } & \multirow[t]{2}{*}{ Breeds } & \multicolumn{4}{|c|}{ Treatments } \\
\hline & & Group I & Group II & Group III & Group IV \\
\hline \multirow{3}{*}{ Nest building (\%) } & Baladi & $100^{\mathrm{a}}$ & $80^{b}$ & $100^{\mathrm{a}}$ & $40^{c}$ \\
\hline & Bouscat & $100^{a}$ & $60^{b}$ & $60^{b}$ & $20^{c}$ \\
\hline & California & $100^{\mathrm{a}}$ & $60^{b}$ & $60^{b}$ & $20^{c}$ \\
\hline \multirow{3}{*}{ Retrieving (\%) } & Baladi & $100^{\mathrm{a}}$ & $100^{\mathrm{a}}$ & $80^{b}$ & $40^{c}$ \\
\hline & Bouscat & $100^{\mathrm{a}}$ & $40^{b}$ & $20^{c}$ & $20^{c}$ \\
\hline & California & $100^{a}$ & $40^{b}$ & $20^{c}$ & $20^{c}$ \\
\hline \multirow{3}{*}{ Physical contact $(\%)$} & Baladi & $100^{\mathrm{a}}$ & $80^{b}$ & $80^{b}$ & $40^{c}$ \\
\hline & Bouscat & $100^{\mathrm{a}}$ & $40^{b}$ & $40^{b}$ & $20^{c}$ \\
\hline & California & $100^{\mathrm{a}}$ & $40^{b}$ & $40^{b}$ & $20^{c}$ \\
\hline \multirow{3}{*}{ Suckling (\%) } & Baladi & $100^{\mathrm{a}}$ & $100^{\mathrm{a}}$ & $80^{b}$ & $40^{c}$ \\
\hline & Bouscat & $100^{\mathrm{a}}$ & $60^{b}$ & $50^{b}$ & $10^{c}$ \\
\hline & California & $100^{\mathrm{a}}$ & $60^{b}$ & $50^{b}$ & $10^{\mathrm{c}}$ \\
\hline
\end{tabular}

Table (5): Abnormal behavioral patterns of the examined does.

\begin{tabular}{|c|c|c|c|c|c|}
\hline \multirow{2}{*}{ Item } & \multirow{2}{*}{ Breeds } & \multicolumn{4}{|c|}{ Treatments } \\
\hline & & Group I & Group II & Group III & Group IV \\
\hline \multirow{3}{*}{ Cannibalism (\%) } & Baladi & $0^{\mathrm{a}}$ & $0^{\mathrm{a}}$ & $0^{a}$ & $20^{b}$ \\
\hline & Bouscat & $0^{a}$ & $0^{a}$ & $20^{b}$ & $60^{c}$ \\
\hline & California & $0^{a}$ & $0^{\mathrm{a}}$ & $20^{b}$ & $40^{c}$ \\
\hline \multirow{3}{*}{ Fur chewing (\%) } & Baladi & $\mathbf{0}$ & $\mathbf{0}$ & $\mathbf{0}$ & $\mathbf{0}$ \\
\hline & Bouscat & 0 & $\mathbf{0}$ & 0 & $\mathbf{0}$ \\
\hline & California & $\mathbf{0}$ & $\mathbf{0}$ & $\mathbf{0}$ & $20^{b}$ \\
\hline \multirow{3}{*}{ Unknown behaviour } & Baladi & No & No & No & No \\
\hline & Bouscat & No & No & No & No \\
\hline & California & No & No & No & No \\
\hline
\end{tabular}

Figures in the same raw with different superscripts differs significantly $(\mathrm{p}<0.01)$.

Group I = Control (Temp. was $21{ }^{\circ} \mathrm{C}$, $\mathrm{RH}$ was $60 \%$ and received the average daily amount of food)

Group II = Temp. was $33{ }^{\circ} \mathrm{C}$ and $\mathrm{RH}$ was $80 \%$

Group III = Received a daily amount of food equals to $75 \%$ of that consumed by the control one

Group V = Received a daily amount of food equals to $50 \%$ of that consumed by the control one

\section{1- Health status of the does:}

Rabbits are especially vulnerable to heat stroke particularly those that are overweight or heavily furred (Sandford, 1996). An increased environmental temperature and high relative humidity, poor ventilation and over crowdness are of the main factors that affect on the health status of rabbits and lead to heat stroke. However, the correct nutrition or nourishment of the domestic rabbits is certainly one of the most important aspects of rabbit keeping quality and to reach the best production, either flesh, kindle or fur (Parigi-Bini et al, 1990).
The data represented in Table (1) showed the effect of increased environmental temperature and relative humidity as well as $25 \%$ and $50 \%$ underfeeding on the health status that estimated by measuring of rectal temperature, respiratory rates and the condition of the mucous membranes of the experimented does.

With regard to rectal temperature, the obtained data revealed that, average rectal temperature of the control does that maintained under normal environmental conditions and received the average daily amount of food were 38.8, 38.6 and $38.9^{\circ} \mathrm{C}$ for Baladi, Bouscat and California breeds, respectively. However, for 
those subjected to an increase in the surrounding environmental temperature and relative humidity $\%$, it recorded an average of 39.1, 39.8 and $39.9^{\circ} \mathrm{C}$ for Baladi, Bouscat and California breeds, respectively. At the same time, the average rectal temperature of the does subjected to $\mathbf{2 5 \%}$ and $\mathbf{5 0 \%}$ underfeeding were $\mathbf{3 8 . 6}$, 37.8, 37.8 and $37.8,37.7,37.6{ }^{\circ} \mathrm{C}$ for Baladi, Bouscat and California breeds, respectively.

With regard to respiratory rates, Table (1) showed that, average respiratory rates of the does that maintained under normal environmental conditions and received the average daily amount of food were 86,88 and 90 movements/minute for Baladi, Bouscat and California breeds, respectively. However, for those subjected to an increase in the environmental temperature and relative humidity \%, the average rates were 93,115 and 110 movements/minute for Baladi, Bouscat and California breeds, respectively. At the same time, the average respiratory rates of the does subjected to $\mathbf{2 5 \%}$ and $\mathbf{5 0 \%}$ underfeeding were 88, 112, 108 and 110, 118, 112 movements / minute for Baladi, Bouscat and California breeds, respectively.

With regard to the condition of the mucous membranes, the data illustrated in the same table indicated that the mucous membranes were normal in colour (rosy red) for the control does that maintained under normal environmental conditions and received the average daily amount of food while the membranes were congested for the does of the Bouscat and California breeds that subjected to an increase in the environmental temperature and relative humidity \%. However, it was still rosy red in does of the Baladi breed of the same group. Moreover, the membranes were pale in colour for the does of the Bouscat and California breeds as a result of their $\mathbf{2 5 \%}$ underfeeding while the colour was pale for all the examined does, either of Baladi, Bouscat or California breed as a result of their $50 \%$ underfeeding.

These data indicated that, the health status of the does of both Bouscat and California breeds was significantly affected $(p<0.01)$ either by thermal increase and high relative humidity, $25 \%$ or $50 \%$ underfeeding while the health status of the examined does of the Baladi breed was significantly affected $(\mathbf{p}<\mathbf{0 . 0 1})$ only when they were subjected to $50 \%$ underfeeding. This finding agreed with Parigi-Bini et al (1990), Roca (1996) and Sandford (1996) indicating the effect of adverse environmental conditions and under nourishment on the health status of rabbits particularly those of overweight breeds.

\section{2- Serum cortisol level of the does:}

Cortisol and corticosterone are the principle glucosides of the adrenal cortex. Cortisol predominates in rabbit, mouse and rat. Large ruminants are intermediate case while cortisol is the major corticosteroid secreted by sheep (Linder, 1959 and Paterson, 1964). Studies on the circulating levels of adrenal corticosteroids showed a marked rise of these levels after exposure to any stressful conditions (Johnson and Van Jonack, 1976; Dantzer and Mormede, 1983; Elizabeth and Huda, 1985; Shutt et al., 1988; Minton and Bleacha, 1990 and Parrott et al., 1996).

The data represented in Table (2) showed the effect of increased environmental temperature and relative humidity $\%, 25 \%$ underfeeding and $50 \%$ underfeeding on the average serum cortisol level of the examined does. These data revealed that, the average serum cortisol level of the does that maintained under normal environmental conditions and received the average daily amount of food were 1.54, 1.61 and $1.59 \mu \mathrm{g} / \mathrm{dl}$ for Baladi, Bouscat and California breeds, respectively. However, for those subjected to an increase in the environmental 
temperature and relative humidity $\%$, the average serum cortisol concentrations were 1.72, 4.63 and 5.11 $\mu \mathrm{g} / \mathrm{dl}$ for Baladi, Bouscat and California breeds, respectively. In the same time, the average serum cortisol level of the does subjected to $\mathbf{2 5 \%}$ and $\mathbf{5 0} \%$ underfeeding were 2.10, 5.13, 5.42 and 4.18, 4.91, 5.12 $\mu \mathrm{g} / \mathrm{dl}$ for Baladi, Bouscat and California breeds, respectively. These data indicated that, average serum cortisol level of the does of both Bouscat and California breeds was significantly affected $(p<0.01)$ either by thermal increase and high relative humidity, $25 \%$ or $50 \%$ underfeeding while that of the examined does of the Baladi breed was significantly affected $(p<0.01)$ only when they were subjected to $50 \%$ underfeeding. These findings indicated that, adverse environment and under nourishment acted as stress factors on rabbits, particularly those of overweight breeds.

\section{3-Viability of the newly born young rabbits:}

When the female is pregnant as well as during lactation, she must supply the adequate amount of food which contains the nutrients necessary for growth of both foeti and young (El-Sheikh, 1998). High mortalities of young were showed in the swine and rat dams of severely food deprivation as maternal starvation severely affects the foetal growth (Anderson et al.,1979; Ezekwe, 1981 and Mervat, 1993). However, young of dams on a high plane of nutrition are more active than those of dams on maintenance or less adequate diets (Houpt et al., 1983). In the same time, litter size and viability of the newly born are greatly affected by the surrounding environment especially the ambient temperature and relative humidity \% (Sandford, 1996).

The data represented in Table (3) showed the effect of increased environmental tempera- ture and relative humidity $\%, 25 \%$ underfeeding and $50 \%$ underfeeding on the litter size, percentage of viability of young at birth, percentage of death of young after one week, percentage of death of young after two weeks and percentage of death of young at weaning.

With regard to litter size (No./birth), the obtained data revealed that, non of these treatments had a significant effect on the litter size, either of Baladi, Bouscat or California breeds.

With regard to viability of young at birth, the data illustrated in Table (3) revealed that, viability of young rabbits at birth when the does were maintained under normal environmental conditions and received the average daily amount of food was $\mathbf{8 0 \%}$, either for Baladi, Bouscat or California breeds. However, for those subjected to an increase in the ambient environmental temperature and relative humidity \%, it were 80, 70 and $70 \%$ for Baladi, Bouscat and California breeds, respectively. In the same time, viability at birth of young of does subjected to $25 \%$ and $50 \%$ underfeeding were $75,60,60$ and 65, 50, $50 \%$ for Baladi, Bouscat and California breeds, respectively.

With regard to percentages of death of young after one week, the data revealed that, percentage of death after one week of young of does that maintained under normal environmental conditions and received the average daily amount of food was zero, either for Baladi, Bouscat or California breeds. However, for those subjected to an increase in the surrounding environmental temperature and relative humidity \%, the mortalities were 20,40 and $\mathbf{5 0 \%}$ for Baladi, Bouscat and California breeds, respectively. At the same time, the percentages of death after one week of young of does subjected to $\mathbf{2 5 \%}$ and $\mathbf{5 0 \%}$ underfeeding were 20, 30, 30 and 20, 40, 50 for Baladi, Bouscat and California breeds, respectively. 
With regard to percentage of death of young after two weeks, the obtained data revealed that, percentage of death after two weeks of young of does that maintained under normal environmental conditions and received the average daily amount of food was zero, either for Baladi, Bouscat or California breeds. However, for those subjected to an increase in the ambient environmental temperature and relative humidity $\%$, the mortalities were 25,50 and 55 for Baladi, Bouscat and California breeds, respectively. In the same time, the percentage of death after two weeks of young of does subjected to $\mathbf{2 5 \%}$ and $\mathbf{5 0 \%}$ underfeeding was 20, 50, 50 and 20, 60, 60 for Baladi, Bouscat and California breeds, respectively.

With regard to percentages of death of young at weaning, the data revealed that, percentage of death at weaning of young of the control does that maintained under normal environmental conditions and received the average daily amount of food was zero, either for Baladi, Bouscat or California breeds. However, for those subjected to an increase in the surrounding environmental temperature and relative humidity $\%$, the mortalities were 30, 60 and 60 for Baladi, Bouscat and California breeds, respectively. At the same time, the percentage of death at weaning of young of does subjected to $25 \%$ and $\mathbf{5 0 \%}$ underfeeding were 25, 60, 60 and 50, 80, 75 for Baladi, Bouscat and California breeds, respectively.

These data indicated that, development and viability of the newly born young rabbit of both of Baladi, Bouscat and California breeds was significantly affected $(p<0.01)$, either by thermal increase and high relative humidity $\%, 25 \%$ or $50 \%$ underfeeding. This finding agreed with Parigi-Bini et al (1990), Roca (1996), Sandford (1996) and El-Sheikh (1998) indicating the effect of adverse environmental conditions and under nourishment on the health status of rabbits and their young.

\section{4- Maternal behaviour of the does :}

It is interesting that behavioural differences were detected among dams that maintained under adverse environmental conditions and received under nourished diet (Scott, 1981). In the present study, The data represented in Table (4) showed the effect of increased environmental temperature and relative humidity $\%, 25 \%$ underfeeding and $\mathbf{5 0 \%}$ underfeeding on the nest building, retrieving, physical contact and suckling behavioural patterns of the examined does.

With regard to nest building, the obtained data revealed that the percentage of nest building of the does that maintained under normal environmental conditions and received the average daily amount of food was $\mathbf{1 0 0}$, either for Baladi, Bouscat or California breeds. However, for those subjected to an increase in the environmental temperature and relative humidity $\%$, the percentages were 80,60 and $60 \%$ for Baladi, Bouscat and California breeds, respectively. At the same time, the percentage of nest building behaviour of does subjected to $25 \%$ and $50 \%$ underfeeding were $100,60,60$ and 40, 20, 20 for Baladi, Bouscat and California breeds, respectively.

With regard to retrieving behaviour, the data illustrated in Table (4) revealed that all the does that maintained under normal environmental conditions and received the average daily amount of food (either of Baladi, Bouscat or California breed) showed this behaviour. However, for those subjected to an increase in the surrounding environmental temperature and relative humidity $\%$, the percentages of the does that perform this behaviour were 100, 40 and 40 for Baladi, Bouscat and California breeds, respectively. At the same time, the percentages of does that subjected to $25 \%$ and $50 \%$ underfeeding and performed this behav- 
iour were 80, 20, 20 and 40, 20, 20 for Baladi, Bouscat and California breeds, respectively.

With regard to the percentage of physical contact between the does and their newly born young, the obtained results revealed that all the does that maintained under normal environmental conditions and received the average daily amount of food (either of Baladi, Bouscat or California breed) showed this behaviour. However, for those subjected to an increase in the surrounding environmental temperature and relative humidity $\%$, the percentages of the does that performed this behaviour were 80, 40 and 40 for Baladi, Bouscat and California breeds, respectively. At the same time, the percentages of does that subjected to $25 \%$ and $50 \%$ underfeeding and perform this behaviour were 80, 40, 40 and 40, 20, 20 for Baladi, Bouscat and California breeds, respectively.

With regard to the percentage of the does that suckle their newly born young at the first day postpartum, the obtained data revealed that all the does that maintained under normal environmental conditions and received the average daily amount of food (either of Baladi, Bouscat or California breeds) suckled their young at the first day postpartum with $100 \%$. However, for those subjected to an increase in the ambient environmental temperature and relative humidity $\%$, the percentages of the does that suckled their newly born young at the first day postpartum was 100, 60 and 60 for Baladi, Bouscat and California breeds, respectively. At the same time, the percentages of does that subjected to $25 \%$ and $50 \%$ underfeeding and suckled their newly born young at the first day postpartum were $80,50,50$ and $40,10,10$ for Baladi, Bouscat and California breeds, respectively.

These data indicated that, maternal behaviour of the does of both Bouscat and California breeds was significantly affected $(p<0.01)$ with a serious degree either by increase in the ambient temperature and high relative humidity, $25 \%$ or $50 \%$ underfeeding while the maternal behaviour of the examined does of the Baladi breed was significantly affected $(p<0.01)$ with all treatments but with a serious degree only when they were subjected to $50 \%$ underfeeding. This finding agreed with Parigi-Bini et al (1990), Roca (1996) and Sandford (1996) indicating the effect of adverse environmental conditions and under nourishment on the maternal behaviour of rabbits especially those of overweight breeds.

\section{5- Abnormal behavioural patterns of the does :}

Exposure to stress is indeed a powerful stimulus that always reflects on the animal with some abnormal behavioural patterns (Dantzer and Mormede, 1983). In the present study, the data represented in Table (5) showed the effect of increased surrounding environmental temperature and relative humidity \%, $25 \%$ underfeeding and $50 \%$ underfeeding on some common abnormal behavioural patterns that are usually done by rabbits (cannibalism, fur chewing as well as any unknown behaviour). The obtained data revealed that the examined does of the Baladi breed were significantly $(p<0.01)$ cannibalize their newly born young only when they were fed on diet $50 \%$ less than the control. However, they did not show fur chewing or any other unknown behaviour, either when they maintained on increased environmental temperature and relative humidity \%, $25 \%$ underfeeding or $\mathbf{5 0 \%}$ underfeeding.

With regard to the examined does of the Bouscat and California breeds, Table (5) indicated that they did not show any abnormal behavioural pattern when they were maintained 
on an increased environmental temperature and relative humidity \%. However, the examined does of both Bouscat and California breeds were significantly $(p<0.01)$ cannibalized their newly born young when they were maintained on $50 \%$ underfeeding while the does of California breed only showed fur chewing with a significant level $(\mathbf{p}<0.01)$ with the same treatment. However, non of the examined does showed any other unknown behaviour, either when they were maintained on an increased environmental temperature and relative humidity $\%, \quad 25 \%$ underfeeding or $\mathbf{5 0 \%}$ underfeeding.

This finding agreed with Jakubowski and Terkel, 1986 (with rats), Cheeke, 1987 (with rabbits), Mervat, 1993 (with rats) and Sandford, 1996 (with rabbits) indicating that adverse environmental conditions as well as underfeeding had a significant effect on the incidence of abnormal behaviour of the rabbits particularly those of overweight breeds.

\section{CONCLUSION :}

The adverse environmental conditions including an increased surrounding ambient temperature and high relative humidity $\%$ as well as maternal feed deprivation had been found to act as stress factors on the does and affect on their health status and alter their maternal behaviour. Moreover, it had also been found to affect the development, viability and survival of the newly born young. This work also supports the idea that any deficiency or deviation in the surrounding environment and / or management of the animal is usually followed by abnormal or behavioural disorders, which consequently affect the performance and health condition of the animal.

\section{REFERENCES :}

1-Afifi, D.S. and Daghash, H.A. (1999): Reproductive performance of California doe rabbits as affected by feeding freshly Nigella Sativa seeds. Alex. J. Vet. Sci., 15 (5): 995 1008.

2-Anderson, L.L.; Hard, D.L. and Kertiles, L.D. (1979): Progesterone secretion and fetal development during prolonged starvation in the pig. Amer. J. Physiol., E. 335 - E. 341.

3-Cheeke, P.R. (1987): Rabbit feeding and nutrition. Academic Press, London.

4-Dandliker, W.B. and Feigen, G.A. (1970): Quantification of the antigen-antibody reaction by polarization immunochemistry. Immunochemistry, 7: 799-828.

5-Dandliker, W.B. and Saussure, D.V. (1973): Review article: fluorescent polarization immunoassay. Theory and experimental method. Immunochemistry, 10: 219-227.

6-Dantzer, R. and Mormede, P. (1983): Stress in farm animals : A need for reevaluation. $J$. Anim. Sci., 57: 6-18.

7-El-Sheikh, A.I. (1998): Effect of mating system on some productive traits of New Zealand white rabbits. Vet. Med. J. Giza, 46 (4B): $673-679$.

8-Elizabeth, A.Y. and Huda, A. (1985): Corticotropin releasing factor stimulation of adrenocorticotropin and B-endorphin release: Effect of acute and chronic stress. Endocrinology, 117: 23-30.

9-Ezekwe, M.O. (1981): Effect of maternal starvation on some blood metabolites, liver glycogen, birth weight and survival of piglets. J. Anim. Sci., 53 (6): 1504 - 1510.

10-Hafez, E.S.E. (1968): Adaptation of domestic animals. Lea and Febiger, Philadelphia.

11-Houpt, K.A.; Hintz, H.F. and Pagan, J.D. (1983): Maternal offspring bond of bonies fed different amounts of energy. Nutr. And Behav., 1: 157 - 168. 
12-Jakubowski and Terkel, J. (1986): Establishment and maintenance of maternal responsivness in postpartum wistar rats. Anim. Behav., 34: 256 - 262.

13-Johnson, H. D. and Van Jonack, W. J. (1976): Effect of environmental and other stressors on blood hormone patterns in lactating animals. J. Dairy Sci., 59:1603-1617.

14-Lee, D.H.K. (1966): The role of attitude in response to environmental stress. J. Social Issues, 12: 83 - 91.

15-Linder, H. R. (1959): Blood cortisol in sheep: Normal concentration and changes in ketosis of pregnancy. Nature, 184, Suppl. 21: 1645.

16-Mervat, M. Kamel (1993): The effect of food deprivation on maternal behaviour and pup development in albino Norway rats. Vet. Med. J. Giza, 41 (1): 123 - 127.

17-Minton, J. E. and Blecha, F. (1990): Effect of acute stressors on endocrinological and immunological functions in lambs. J. Anim. Sci., 68: 3145 - 3151.

18-Numan, M. (1978): Progesterone inhibition of maternal behaviour in the rat. Hormones and Behaviour, 11: 209 - 231.

19-Ojamaa, K.M.; Elliot, J.I. and Hartsock, T.G. (1980): Effect of gestation feeding level on glycogen reserves and blood parameters in the newborn pig. J. Anim. Sci., 51 (3): 620 628.

20-Parigi-Bini, R.; Xiccato, G. and Cinetto, M. (1990): Energy and protein retention and partition in rabbit does during pregnancy. Cuni-Sci., 6 (1): 19.
21-Parrott, R.F. ; Lioyd, D. M. and Goode, J. A. (1996): Stress hormone responses of sheep to food and water deprivation at high and low ambient temperatures. Animal Welfare, 5: 4556 .

22-Paterson, J. Y. F. (1964): The distribution and turnover of cortisol in sheep. J. Endocrinol., 28: 183.

23-Roca, T. (1996): Calculated cost of reproduction in rabbit breeding. Cuniculture, 129: 9698.

24-Sandford, J.C. (1996): The domestic rabbit. $5^{\text {th }}$ Ed., Blackwell Science Ltd, Oxford.

25-SAS (1995): Statistical analysis system. User's Guide: Statistics. Version 6, $2^{\text {nd }}$ Ed., SAS Inst. Inc. , Cary, NC.

26-Scott, G.H. (1981): What is animal stress and how it is measured. J Anim. Sci., 52 (1): 150 153

27-Shutt, D. A. ; Smith, A. I. ; Wallace, C. A. ; Connell, R. and Fell, L. R. (1988): Effect of Myiasis and acute restraint stress on plasma levels of immunoreactive B-Endorphin, adrenocorticotrophin and cortisol in sheep. Aust. J. Biol. Sci. , 41: 297-301.

28-Suckow, M.A. and Douglas, F.A. (1997): The laboratory rabbit. CRC Press, Boca Raton, New York.

29-Tonkiss, J and Smart, J.L. (1983): Discrimination learning in pigmented albino rats following early life under nutrition. Nutr. and Behav., 1: 207 - 221.

30-Willis, M.B. (1991): Dalton`s introduction to practical animal breeding. Blackwell Science, Oxford. 
تأثير بعض مسببات الإجهاد المناخية وكذلك الحد من كمية الغذاء على الحالة الصحية

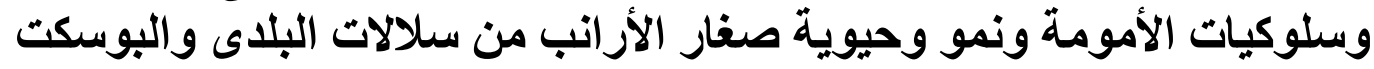
والكاليفورنيا

معتز أحمد محمد عبد الرحمن** ، مصطقى محمد أحمد* ، مديحه درويش" والئورنا "قسم صحة الحيوان- كلية الطب البيطرى - جامعة أسيوط.

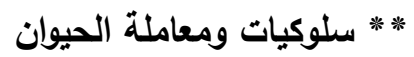

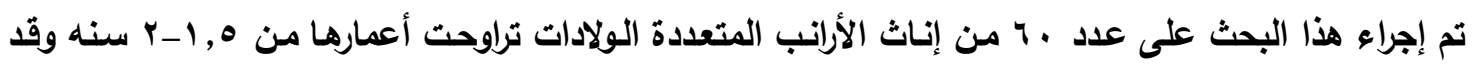

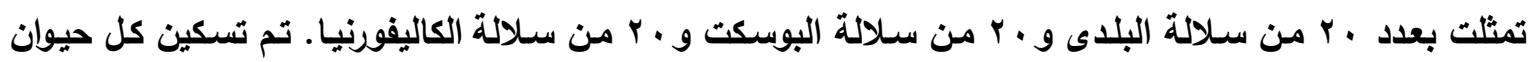

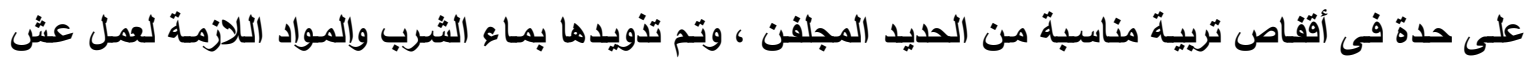

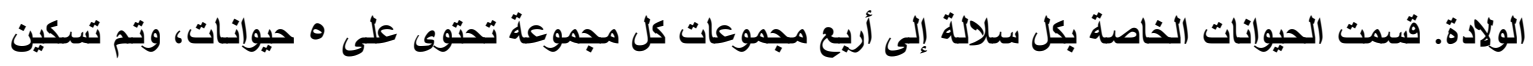

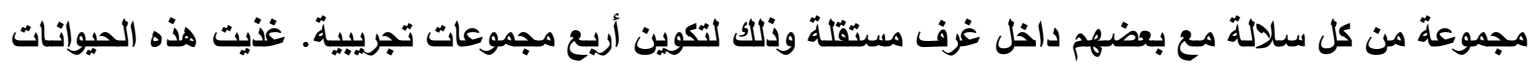

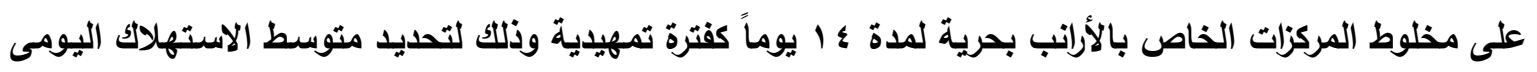

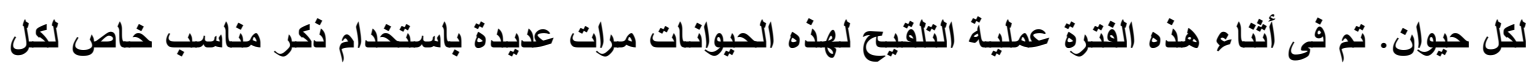

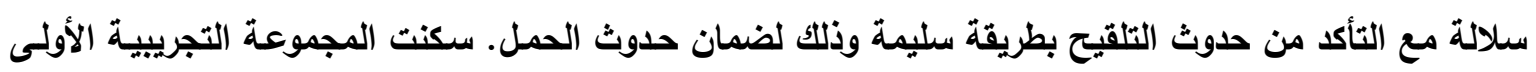

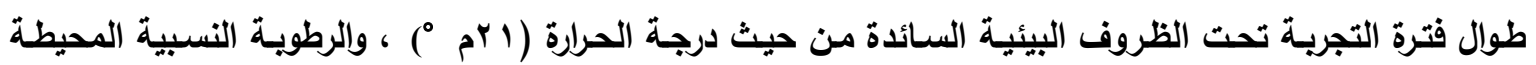

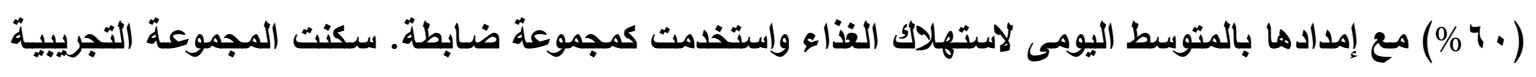

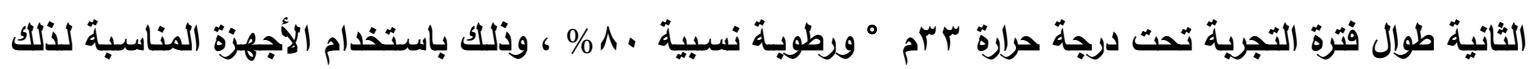

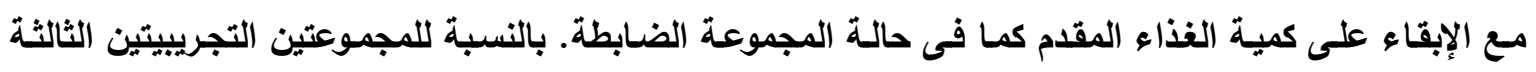

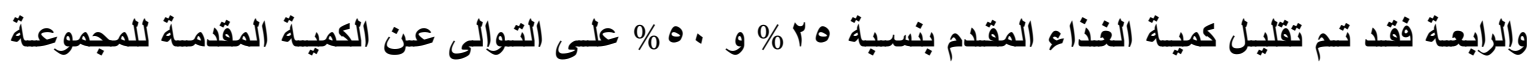

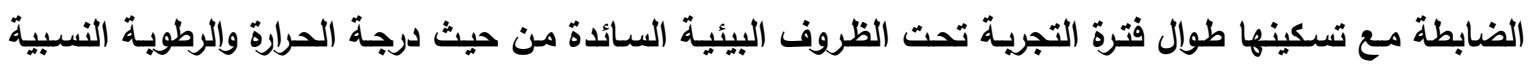

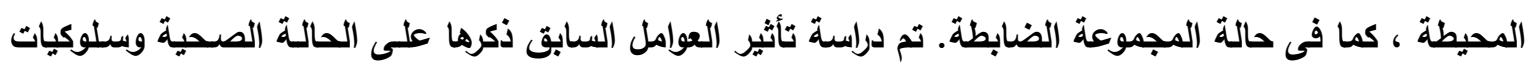

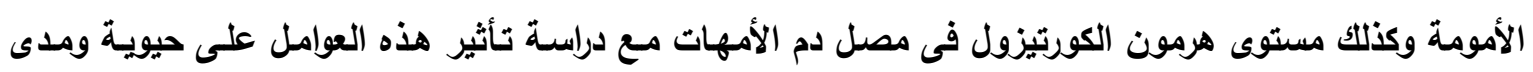
مقاومة الصغار حتى الفطام.

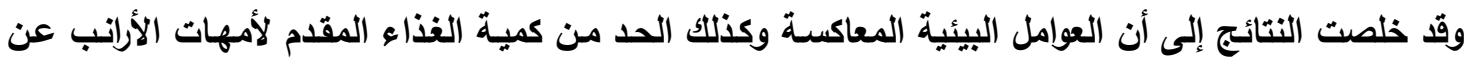

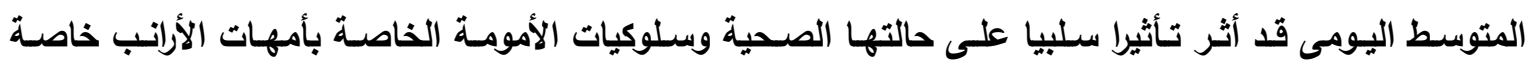

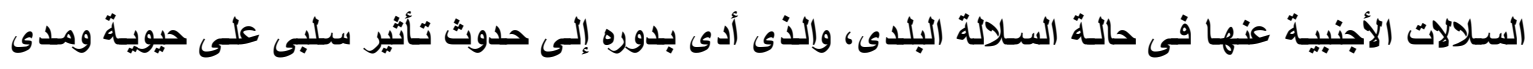

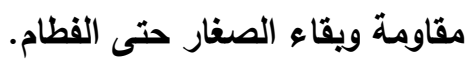

